\title{
Design and Control of Alkali-Gatalyzed Transesterification Reactors
}

\author{
Veerayut Lersbamrungsuk *,1 \\ Thongchai Srinophakun ${ }^{2}$ \\ ${ }^{1}$ Department of Chemical Engineering, Faculty of Engineering and Industrial Technology, \\ Silpakorn University, Nakhon Pathom, 73000, Thailand \\ ${ }^{2}$ Department of Chemical Engineering, Faculty of Engineering, Kasetsart University, \\ Bangkok, 10900, Thailand \\ *e-mail : veerayut@su.ac.th
}

Controllability analysis during the design stage is needed to ensure that the plant can be operated properly. This research focuses on design and control of transesterification reactor. Effects of important design parameters including residence time, methanol/oil molar ratio, and reactor temperature to design conversion and controllability of the reactor are studied. Controllability is analyzed using linear system theory based on poles, zeros, and gains. The result reveals that for a given design conversion, the operation with high reactor temperature and low methanol/oil molar ratio is preferred.

Keywords : Alkali-catalyzed, Biodiesel, Controllability, Design and Control, Transesterification reactor

\section{INTRODUCTION}

Increase of energy demand results in the reduction of petroleum-based fuels and this makes a considerable interest in research on renewable energy. Biodiesel, derived from vegetable oil or animal fats, is recommended for use as a substitute for petroleum-based diesel. Although the use of biodiesel as a fuel has been widely investigated, there are only few researches studying on the control design of biodiesel production processes.

The analysis of controllability during the process design has been criticized by many experts. Shinskey (1982) noted that "the plant may be uncontrollable even though the process design appears satisfactory from a steady-state point of view". Morari (1992) pointed out that some simple controllability criteria should be included within synthesis procedures. Skogestad and Postlethwaite (2005) stated that "Controllability is independent of the controller, and is a property of the plant (or process) alone. It can only be affected by changing the plant itself; that is, by (plant) design changes".

This research focuses on design and control of transesterification reactor. Effects of important design parameters including reactor residence time, methanol/oil molar ratio, and reactor temperature on design 
conversion and controllability will be studied.

\section{THEORY (or EXPERIMENTAL)}

\section{Transesterification Reactions}

In this research alkali-catalyzed transesterification is considered because it is the most widely used method. The transesterification consists of a sequence of three reversible reactions (Freedman et al., 1986; Noureddini and Zhu, 1997) as shown in Figure 1. The reaction involves the decomposition of triglyceride (TG) by methanol $(\mathrm{MeOH})$ as diglyceride (DG) and monoglyceride (MG) with glycerol $(\mathrm{GL})$ and fatty acid methylester (FAME) as products. The stoichiometry of the overall reaction shows that three molecules of methanol is required to react with one molecule of triglyceride and this produces one molecule of glycerol and three molecules of fatty acid methylester.

$$
\begin{aligned}
& \mathrm{TG}+\mathrm{MeOH} \quad \stackrel{\stackrel{\mathrm{k}_{1}}{\leftrightarrow}}{\mathrm{k}_{2}} \mathrm{DG}+\mathrm{FAME} \\
& \mathrm{DG}+\mathrm{MeOH} \underset{\mathrm{k}_{4}}{\stackrel{\mathrm{k}_{3}}{\leftrightarrow}} \mathrm{MG}+\mathrm{FAME} \\
& M G+M e O H \quad \stackrel{\mathrm{k}_{5}}{\stackrel{\mathrm{k}_{6}}{\leftrightarrows}} \mathrm{GL}+\mathrm{FAME} \\
& \mathrm{TG}+3 \mathrm{MeOH} \leftrightarrow \mathrm{GL}+3 \mathrm{FAME}
\end{aligned}
$$

Fig. 1: Transesterification Reaction

In general, large amount of methanol is required to shift reaction equilibrium to produce more FAME. The reaction near the boiling point of methanol $(\sim 338 \mathrm{~K})$ is recommended. Many studies (e.g.
Freedman et al., 1984; Noureddini and Zhu, 1991) have reported that for 333-338 K reaction temperature and 6:1 methanol:oil molar ratio, $90-98 \%$ oil conversion can be given within $90 \mathrm{~min}$.

The Kinetic model of transesterification has been proposed by several researchers. However, in this research the kinetic model of Noureddini and Zhu (1997) will be used.

\section{Mathematical model of} transesterification reactor

To study effects of design parameters, a mathematical model of transesterification reactor need to be derived. It is assumed that the reactor consists of two inlet streams of virgin oil and pure methanol. The reactor is in a well-mixed condition and its volume holdup is constant. The reactor operation is isothermal and triglyceride is assumed as triolein. The model can be written as equations $1 a-1 f$.

$$
\begin{aligned}
& \frac{d V C_{T G}}{d t}=F_{T G, i n} C_{T G, i n}-F C_{T G}-r_{1} V \\
& \begin{array}{c}
\frac{d V C_{M e O H}}{d t}=F_{M e O H, i n} C_{M e O H, i n} \\
-F C_{M e O H}-r_{1} V \\
-r_{2} V-r_{3} V
\end{array} \\
& \begin{aligned}
\frac{d V C_{D G}}{d t}=-F m_{D G}+r_{1} V-r_{2} V \\
\frac{d V C_{M G}}{d t}=-F C_{M G}+r_{2} V-r_{3} V
\end{aligned}
\end{aligned}
$$

$\frac{d V C_{F A M E}}{d t}=-F C_{F A M E}+r_{1} V+r_{2} V+r_{3} V$

$\frac{d V C_{G L}}{d t}=-F C_{G L}+r_{3} V$ 
where $C_{\{i\}}$ and $F_{\{i\}}$ denote concentration ( $\mathrm{mol} / \mathrm{l})$ and volumetric flow rate $(\mathrm{l} / \mathrm{min})$ of component $\{i\}$, respectively. $V$ is reactor volume holdup $(\mathrm{I})$ and $\mathrm{F}$ is volumetric flow rate $(1 / \mathrm{min}) . r_{1}, r_{2}$, and $r_{3}$ denote reaction rates of the three reversible reactions.

\section{RESULTS AND DISCUSSION}

\section{Design of transesterification reactor}

The molar flow rate of oil used here is $19.8 \mathrm{~mol} / \mathrm{min}$ (taken fom Zhang et al., 2003). Balat and Balat (2010) pointed out that three important design parameters of transesterification reactor are residence time, reactor temperature, and methanol/oil feed molar ratio. Effects of these parameters to reactor conversion can be given by solving the proposed mathematical model at steady state condition of the reactor as shown in Figure 2.

Our result shows that for $60 \mathrm{~min}$ residence time it is difficult to achieve over
95\% conversion, that is, very high temperature and very high methanol/oil ratio are required. Hence, $120 \mathrm{~min}$ residence time is chosen. Figure 2 shows the contour plot of conversion and illustrate the dependency of conversion to reaction temperature and methanol/oil molar ratio for $120 \mathrm{~min}$ residence time. Note that there will be several possible operating conditions to achieve a given conversion. For example, for 95\% conversion, one may choose high temperature operation with $338.15 \mathrm{~K}$ the temperature and 9:1 the molar ratio or low temperature operation with $313.15 \mathrm{~K}$ and 16:1 the molar ratio. In general, in design based economic purpose, less the molar ratio is preferred to reduce the recycle cost of excess methanol. However, a good in economic sense may not be good in terms of control. Hence, controllability of these operating conditions will be considered next.

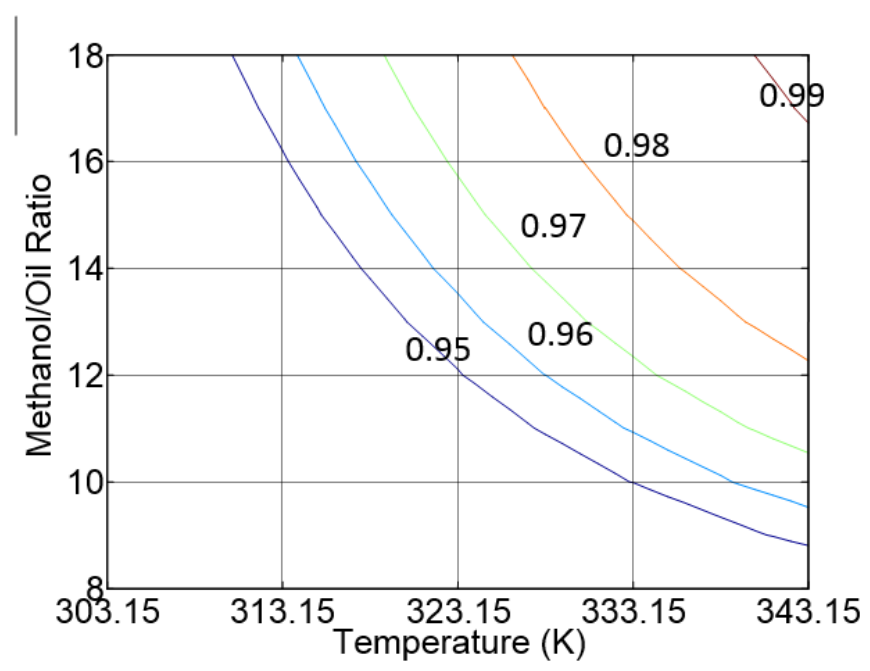

Fig. 2: Effect of reaction temperature and methanol/oil molar ratio to conversion for 120 min residence time 


\section{Controllability of transesterification reactor}

Controllability of transesterification reactor for a given conversion will be analyzed using linear system theory based on poles, zeros, and gains. In the analysis, controlled output and manipulated input are assumes as concentration of FAME and reactor temperature, respectively. The oil feedrate is defined as disturbance. Because the gain is dependent of scaling, $\pm 10 \%$ allowed change of FAME concentration, \pm 5 $\mathrm{K}$ allowed change of reactor temperature, and $\pm 10 \%$ allowed change of oil feedrate are assumed.

Table 1 shows effects of operating parameters to controllability of the reactor for $95 \%$ oil conversion. The poles are all negative for all operating conditions and this implies the reactor is a stable system. Furthermore, the condition $C$ has the largest poles and this means more stability and fast dynamics can be expected. This should be because at higher temperature the reaction is faster. However, for the process gains only small difference is observed.

In terms of zeros, changes of oil feedrate may introduce inverse-response due to the existence of a right-half-plane (RHP) zero. Inverse response can happen when there are two parallel opposing effects. For this case, an increase of oil feedrate is fast and initially reduces reaction time resulting in drop of FAME production. However, an increase of oil feedrate introduces gradually more oil to the reactor resulting in the raise of FAME. The inverse response can happen for all operating conditions and this cannot be avoid.

For all operating conditions, the process gains are much higher than the disturbance gains and this means that when the production rate (oil feedrate) changes it is very easy to keep the FAME concentration at the desired value by manipulating the reactor temperature.

Based on our analysis, for control purpose the high temperature operation is better in terms of fast dynamic. This

Table 1. Effect of design parameters to controllability of the reactor for $95 \%$ oil conversion with 120 min residence time

\begin{tabular}{|c|c|c|c|}
\hline $\begin{array}{l}\text { Operating } \\
\text { conditions }\end{array}$ & $\begin{array}{c}\text { Condition } \mathrm{A}: \\
\mathrm{T}=313.15 \mathrm{~K} \\
\text { ratio }=17: 1\end{array}$ & $\begin{array}{c}\text { Condition B: } \\
\mathrm{T}=318.15 \mathrm{~K} \\
\text { ratio }=13: 1\end{array}$ & $\begin{array}{c}\text { Condition C: } \\
\mathrm{T}=338.15 \mathrm{~K} \\
\text { ratio }=9: 1\end{array}$ \\
\hline \multirow{4}{*}{ Poles } & -9854 & -12470 & -27871 \\
\hline & -1932 & -2085 & -3075 \\
\hline & -617 & -620 & -886 \\
\hline & -32 & -29 & -26 \\
\hline Process zeros & all negatives & all negatives & all negatives \\
\hline Disturbance zero & one RHP zero & one RHP zero & one RHP zero \\
\hline Process gain & 6.17 & 6.02 & 6.12 \\
\hline Disturbance gain & 0.42 & 0.35 & 0.27 \\
\hline
\end{tabular}


operation is in agreement with the design based economic purpose where higher the temperature and lesser the ratio is preferred to reduce recovery cost of excess methanol.

\section{CONCLUSION}

In this research, design and control of transesterification reactor is considered. Effects of important design parameters including residence time, reactor temperature, and methanol/oil molar ratio to design conversion and controllability are analyzed. The results show that the operation with high the temperature and low the ratio is preferred in terms of both economic and controllability purposes.

\section{ACKNOWLEDGEMENT}

The authors acknowledge the fund from TRF Grant for New Scholar "MRG5380286" supported by Thailand Research Fund, Office of the Higher Education Commission, and Silpakorn University.

\section{REFERENCES}

1. Balat M., and Balat H. (2010). Progress in biodiesel processing, Applied Energy, 87: 1815-1835.

2. Freedman B., Butterfield R.O., and Pryde E.H. (1986). Transesterification kinetics of soybean oil, JAOCS, 63(10): 13751380.

3. Morari M.(1992). Effect of design on the controllability of chemical plants. In IFAC Workshop on interactions between process design and control, London, England, 3-16.
4. Noureddini H., and Zhu D. (1977). Kinetics of transesterification of soybean oil, JAOCS, 74(11): 1457-1463.

5. Shinskey F.G. (1982). Uncontrollable processes and what to do about them. In AlChE Annual Meeting, Los Angeles, US, 13-18.

6. Skogestad, S., and Postlethwaite, I. (2005). Multivariable Feedback Control: Analysis and Design. $2^{\text {nd }}$ ed. John Wiley \& Sons, Chichester, England.

7. Zhang Y., Dube M.A., McLean, D.D., and Kates M. (2003). Biodiesel production from waste cooking oil: 1 . Process design and technological assessment. Bioresource Technology, 90: 229-240. 